\title{
Incidência de afecções reprodutivas em fêmeas bovinas submetidas ao abate no sul do estado do Espírito Santo
}

Larissa Marchiori Sena, Ítalo Câmara de Almeida", Nara Clara Lazaroni e Merchid, Jacymara Dutra Santos, Maria Augusta Pires da Luz Chieppe, Bianca Carvalho dos Santos Albuquerque, Nathalia Viana Tamiasso, José de Oliveira Carvalho, Carla Braga Martins

Centro de Ciências Agrárias e Engenharias, Universidade Federal do Espírito Santo (UFES), Vitória, ES, Brasil

*Autor correspondente

e-mail: almeidaicvet@gmail.com

\section{Resumo}

A diminuição da eficiência reprodutiva bovina pode ser atribuída a vários fatores de caráter infeccioso ou não, problemas degenerativos ou, ainda, devido a erros de manejo e nutrição. As desordens reprodutivas são consideradas as principais causas de diminuição da eficiência reprodutiva e descarte precoce dos animais, gerando inúmeras perdas econômicas ao setor do agronegócio. Dessa forma, objetivou-se caracterizar as principais afecções reprodutivas por meio de avaliações macroscópicas, citológicas e histológicas de tratos reprodutivos de fêmeas bovinas abatidas em matadouros. 0 presente estudo foi aprovado pelo Comitê de Ética de Uso de Animais (CEUA/UFES), sob o número 76/2015. Foram obtidos 171 tratos reprodutivos de matadouro frigorífico. Dentre os aspectos macroscópicos, foram avaliadas alterações relacionadas à morfologia, consistência e coloração em útero, ovário, cérvix, vulva e vagina. As infecções uterinas clínicas foram diagnosticadas pela presença de secreção no interior do útero, enquanto as infecções uterinas subclínicas foram diagnosticadas por meio da citologia endometrial, com base no percentual de neutrófilos, a partir da contagem de 200 células. Classificou-se como infecção subclínica a presença acima de 3\% de neutrófilos. Na análise histopatológica, as mesmas foram denominadas endometrites, metrites, perimetrites e miometrites de acordo com a camada uterina afetada. Ooforites foram diagnosticadas macroscopicamente pela presença de sinais inflamatórios e conteúdo fétido no ovário. Estruturas entre 18 e $25 \mathrm{~mm}$ foram denominadas cistos ovarianos, sendo divididos em: cistos foliculares, quando apresentaram parede delgada e conteúdo de coloração amarelada, e cistos luteais, quando apresentaram parede espessa e conteúdo de coloração âmbar. Os resultados foram submetidos à análise estatística descritiva. Infecções uterinas estiverem presentes em 12,28\% $(n=21)$ dos animais, sendo 4,09\% $(n=7)$ designadas subclínicas e 8,18\% (n=14) designadas infecções uterinas clínicas. Todos os resultados obtidos na análise macroscópica e citológica foram confirmados pela histopatologia uterina. Nesta avaliação, 100\% (n = 21) 
das infecções foram classificadas como endometrites, a partir da presença de infiltrados polimorfonucleares no endométrio. Ooforites foram encontradas em $1,75 \%(n=3)$ dos animais avaliados, sendo que em dois destes $(1,16 \%)$ havia processo inflamatório uterino concomitante, podendo as infecções ovarianas serem secundárias à contaminação uterina e vice-versa. Cistos ovarianos foliculares estiveram presentes em 2,33\% $(n=4)$. Agenesia unilateral, hipoplasia e fibroses ovarianas foram observadas em 0,58\% ( $n=1)$. Não foram encontradas alterações em cérvix, vulva e vagina. As endometrites clínicas e subclínicas foram as afecções mais observadas nos tratos reprodutivos avaliados. 